\title{
A qualitative impairment in face perception in Alzheimer's disease: Evidence from a reduced face inversion effect
}

\author{
Marie Maxime Lavallée ${ }^{1,2}$, Delphine Gandini ${ }^{1,2}$, Isabelle Rouleau ${ }^{3,4}$, Guillaume T. Vallet ${ }^{1,2}$, Maude \\ Joannette $^{1,2}$, Marie-Jeanne Kergoat ${ }^{5,6}$, Thomas Busigny ${ }^{7,8}$, Bruno Rossion ${ }^{8}$, Sven Joubert ${ }^{1,2}$
}

1 Département de psychologie, Université de Montréal, Montréal, Canada

2 Centre de recherche Institut universitaire de gériatrie de Montréal (CRIUGM), Montréal, Canada

3 Département de psychologie, Université du Québec à Montréal, Montréal, Canada

4 Centre de recherche du Centre hospitalier universitaire de Montréal (CHUM), Montréal, Canada

5 Département de médecine, Université de Montréal, Montréal, Canada

6 Clinique de cognition, Institut universitaire de gériatrie de Montréal, Montréal, Canada

7 CHU Purpan, Toulouse, France

8 Institut de Recherche en Sciences Psychologique et institut de Neuroscience, Université Catholique de Louvain, Louvain-la-Neuve, Belgium

Corresponding author: Dr. Sven Joubert, CRIUGM, 4565 Queen-Mary road, Montréal, Quebec, H3W 1W5, Canada. Tel: 514-340-3540, ext. 3551; sven.joubert@umontreal.ca

Key words: Alzheimer's disease, face recognition, face inversion effect, visuoperceptual processing, vision

Number of words: 5391

Short title (running head): face inversion effect in Alzheimer's disease

(C) 


\begin{abstract}
Prevalent face recognition difficulties in Alzheimer disease have typically been attributed to the underlying episodic and semantic memory impairment. The aim of the current study was to determine if $\mathrm{AD}$ patients are also impaired at the perceptual level for faces, more specifically at extracting a visual representation of an individual face. To address this question, we investigated the matching of simultaneously presented individual faces and of other nonface familiar shapes (cars), at both upright and inverted orientation, in a group of mild AD patients and in a group of healthy older controls matched for age and education. AD patients showed a reduced inversion effect (i.e. larger performance for upright than inverted stimuli) for faces, but not for cars, both in terms of error rates and response times. While healthy participants showed a much larger decrease in performance for faces than for cars with inversion, the inversion effect did not differ significantly for faces and cars in AD. This abnormal inversion effect for faces was observed in a large subset of individual patients with $\mathrm{AD}$. These results suggest that $\mathrm{AD}$ patients have deficits in higher-level visual processes, more specifically at perceiving individual faces, a function that relies on holistic representations specific to upright face stimuli. These deficits, combined with their memory impairment, may contribute to the difficulties in recognizing familiar people that are often reported in patients suffering from the disease and by their caregivers.
\end{abstract}




\section{Introduction}

Alzheimer's disease (AD) accounts for approximately $60 \%$ of all dementia cases and is by far the most prevalent form of dementia. Considering the general aging of the population and the fact that age is the greatest risk factor for $\mathrm{AD}$, the expected number of cases is going to double between 2020 and 2040 [1]. Consequently, there is an important need to better understand the nature of the cognitive symptoms that occur in the disease. Ultimately, this may lead to the development of specific cognitive interventions aimed at remediating the difficulties experienced by individuals living with AD.

$\mathrm{AD}$ is typically characterized by memory problems [2]. However, one of the most striking symptoms of $\mathrm{AD}$ is the failure to recognize familiar people [3, 4], a function that relies heavily on visual inputs, especially the persons' faces, rather than auditory inputs (i.e., voices). In $\mathrm{AD}$, the impaired ability to recognize familiar persons has typically been attributed to the underlying memory impairment [5]. Indeed, deficits in both anterograde episodic memory of faces $[6,7]$ and retrograde semantic memory of famous persons $[8-10]$ are present in $\mathrm{AD}$ and are thought to account for the difficulties in recognizing familiar faces.

In addition to their memory impairment, however, deficits in visual tasks are also commonly reported in AD [11]. For instance, individuals suffering from AD have difficulties in color and depth perception [11], visuospatial organization [12], control of visual attention [13] and in visual search tasks with simple stimuli [14]. These low-level visual deficits occur independently of memory problems in $\mathrm{AD}$ [15] and may result from the concentration of neuropathology in the visual cortex [16].

A number of studies have also found deficits at processing pictures of unfamiliar faces. One line of evidence comes from studies which have demonstrated difficulties in the categorization of facial emotions in $\mathrm{AD}$ [17-22]. Another line of evidence involves studies that have shown deficits in the processing of non-emotional features of faces such as age 
estimation [23] and mental rotation of faces [24]. AD patients also show poorer accuracy at the Benton Facial Recognition Test (BFRT) [25], a test which requires matching unfamiliar faces simultaneously presented under identical and different views [26-28], this impairment being observed even when visual contrast has been increased [29].

However, even when unfamiliar faces are used in simple matching tasks minimizing memory processes, there is no evidence that AD's deficits at such tasks reflect an impairment that is specific to faces, i.e., which would not concern other visual shapes. Most importantly, such explicit matching tasks require attention, complex stimulus comparison and decision processes. Hence, reduced performance at such tasks does not provide unambiguous evidence that AD patients are impaired at the perceptual level for faces, i.e. that they are impaired at building a visual representation of an individual face (irrespective its long-term familiarity).

One way to address these important issues is to compare AD patients' processing of simultaneously presented individual faces to other nonface familiar shapes, at both upright and inverted orientation. Starting with Yin [30], many studies have shown that the processing of individual faces is much more severely impaired by picture-plane inversion than the processing of other objects [31-43]: this effect has been coined the Face Inversion Effect (FIE) [30, 43, 44 for review]. Although the original study of Yin [30] and others [42] relied on old/new paradigms involving an important memory component, studies have shown a large decrease of performance for inverted unfamiliar faces in delayed or even simultaneous matching tasks with unfamiliar faces [e.g., 32, 33, 40, 45-53], suggesting that the source of the FIE lies at the perceptual level $[48,54,55]$ : the visual representation of an individual face, irrespective of its long-term familiarity, appears to be qualitatively different for upright and inverted faces.

Given these well-established findings in the typical population, the FIE offers a unique opportunity to test whether, in addition to their memory impairment, AD patients have 
deficits in higher-level visual processes such as the perception of individual faces. This is the main goal of the present study. In addition, providing that the answer to this question is positive, we were also interested to test whether such impairments may possibly account in part for the commonly reported difficulties of patients in recognizing familiar persons. Such findings would shed light on the nature of the face processing impairment in AD.

\section{Materials and methods}

Participants. Two groups of participants took part in the study: 25 mild AD patients and 23 healthy older controls (HE). All participants gave written consent before participation, and the research protocol was approved by the Research Ethics Board of the Institut Universitaire de Gériatrie de Montréal (IUGM) and the Centre Hospitalier Universitaire de Montréal (CHUM).

The twenty-five persons (15 women and 10 men) who received a diagnosis of AD were referred by the Cognition clinic of the IUGM and CHUM. Diagnosis of AD complied with the National Institute of Neurological and Communicative Disorders and Stroke and the Alzheimer's Disease and Related Disorders Association (NINCDS-ADRDA) criteria [56]. All patients were in a mild stage of the disease [57] (see Table 1 for details). AD patients completed a neuropsychological assessment, results of which are presented in Table 1 . In addition, $23 \mathrm{HE}$ (13 women and 10 men) participated in the study. They were recruited from a pool of volunteer participants at the CRIUGM. All HE showed normal performance on neuropsychological tests (see Table 1). As part of the neuropsychological assessment, one HE did not complete the Stroop Test. In addition, one AD patient did not complete the Stroop Test; another did not complete the Stroop Test and the Trail Making Test; finally, one AD patient was only able to complete the MMSE, the BLOT, and the VOSP subtests as part of the neuropsychological assessment. These patients were not able to complete all neuropsychological assessment due to fatigue/lack of motivation. HE and AD participants 
were matched for age and level of education. We excluded HE and AD participants who had a presence or history of neurological disorder excluding AD, psychiatric disorder, closed-head injury, a history of alcoholism, substance abuse, general anaesthesia in the past 12 months, an untreated medical or metabolic condition with a potential impact on cognition, uncorrected hearing or vision impairment, as well as eye diseases such as age-related macular degeneration and cataracts.

Neuropsychological assessment. Both groups underwent a general neuropsychological assessment, which included standard measures of memory, language, attention, executive functions, visuoconstructional, visuoperceptual and visuospatial skills. Episodic memory was assessed with the RL/RI 16 [58], a verbal free and cued recall test of single words widely used in the French speaking population. Visual memory was tested using the immediate and delayed recall conditions of the Rey complex figure [59], as well as the immediate and delayed conditions of the DMS48 [60], a visual recognition memory test. Language was assessed with the DO80 picture naming test [61], lexical fluency (letter P) and categorical fluency (animals) [62]. Executive functions were measured using the Trail Making Test A and B [63] and the Victoria Stroop Test [64]. Short term/working memory was assessed using the forward and backward digit span subtest of the Wechsler Memory Scale-III [65]. Visuoconstructional skills were measured with the copy of Rey-Osterrieth figure [59]. Visual perceptual skills were assessed using the Shape detection, Silhouettes, Object decision, and Cubes subtests of the Visual Object and Space Perception battery (VOSP) [66]. In addition, basic-level face recognition abilities were tested using the Benton Facial Recognition test (BFRT) [25]. Finally, visuospatial skills were assessed with the Benton Line Orientation Test [67]. Results are presented in Table 1. 
Table 1. Neuropsychological results of participants.

\begin{tabular}{|c|c|c|c|}
\hline & $\begin{array}{l}\text { Control Mean (S.D.) } \\
\text { [Range] }\end{array}$ & $\begin{array}{l}\text { AD Mean (S.D.) } \\
\text { [Range }]\end{array}$ & $\begin{array}{l}p \text { value for } \\
\text { group effect }\end{array}$ \\
\hline \multicolumn{4}{|l|}{ Demographic data } \\
\hline Age & $77.82(6.4)[65-87]$ & 77.07 (7.62) [54-85] & n.s. \\
\hline Education & 14.23 (2.9) [9-20] & $12.71(3.8)[6-20]$ & n.s. \\
\hline \multicolumn{4}{|l|}{ General cognitive functioning } \\
\hline MMSE & $28.76(1.1)[26-30]$ & $25.17(2.5)[20-29]$ & $p<0.01$ \\
\hline \multicolumn{4}{|l|}{ Memory } \\
\hline \multicolumn{4}{|l|}{ RL/RI 16} \\
\hline Immediate free recall of a word list (16) & $8.40(2.3)[4-13]$ & $2.55(1.8)[0-6]$ & $p<0.01$ \\
\hline Immediate total recall of a word list (16) & $14.40(2.4)[7-16]$ & $6.5(2.6)[2-11]$ & $p<0.01$ \\
\hline Delayed free recall of a word list (16) & $12.24(2.9)[3-16]$ & $1.36(1.5)[0-5]$ & $p<0.01$ \\
\hline Delayed total recall of a word list (16) & $15.56(1.3)[10-16]$ & $6.50(3.3)[0-12]$ & $p<0.01$ \\
\hline \multicolumn{4}{|l|}{ Visual memory } \\
\hline DMS48 Set 1 & $95.15(5.1)[83-100]$ & $76.17(13.5)[50-98]$ & $p<0.01$ \\
\hline DMS48 Set 2 & $93.52(5.9)[83-100]$ & $72.30(14.0)$ [48-96] & $p<0.01$ \\
\hline Rey-Osterrieth immediate recall (36) & $14.80(7.5)[4-30]$ & $4.20(4.2)[0-13]$ & $p<0.01$ \\
\hline Rey-Osterrieth delayed recall (36) & $13.64(7.1)[4-28]$ & $3.78(4.5)[0-14]$ & $p<0.01$ \\
\hline \multicolumn{4}{|l|}{ Executive function/working memory } \\
\hline \multicolumn{4}{|l|}{ Stroop-Victoria Test } \\
\hline Part A & $51.80(10.0)[42-85]$ & $61.62(18.1)[34-101]$ & $p=0.03$ \\
\hline Part B & $82.64(16.0)[57-101]$ & $113.57(36.2)$ [70-192] & $p<0.01$ \\
\hline Part C (interference) & $138.44(27.3)[91-177]$ & $219.81(82.8)[121-392]$ & $p<0.01$ \\
\hline Digit span forward & $6.52(1.4)[4-9]$ & $6.14(1.0)[4-8]$ & n.s. \\
\hline Digit span backward & $5.04(1.49)[3-8]$ & $4.18(1.1)[2-6]$ & $p=0.03$ \\
\hline \multicolumn{4}{|l|}{ Trail Making Test } \\
\hline Part A & $50.20(21.20)[17-113]$ & $69.90(23.4)[32-111]$ & $p<0.01$ \\
\hline Part B & $103.92(36.20)[54-183]$ & $248.81(204.0)$ [72-919] & $p<0.01$ \\
\hline \multicolumn{4}{|l|}{ Language } \\
\hline DO80 & 78.85 (1.7) [75-80] & 74.39 (4.5) [63-80] & $p<0.01$ \\
\hline Verbal fluency "P" in 2 min & $23.96(7.7)[11-42]$ & $14.78(4.6)[6-25]$ & $p<0.01$ \\
\hline Category fluency "animals" in $2 \mathrm{~min}$ & $26.36(4.9)[19-35]$ & $16.52(4.6)[7-26]$ & $p<0.01$ \\
\hline \multicolumn{4}{|l|}{$\begin{array}{l}\text { Visuoperceptual, visuoconstructional } \\
\text { and visuospatial abilities }\end{array}$} \\
\hline \multicolumn{4}{|l|}{ Visual object and space perception battery } \\
\hline Shape detection & $19.69(0.6)[18-20]$ & $19.61(0.6)[18-20]$ & n.s. \\
\hline Silhouette & $19.00(3.9)[10-27]$ & $15.43(3.8)[7-22]$ & $p<0.01$ \\
\hline Object decision & $16.85(1.9)[13-20]$ & $15.48(3.5)[4-20]$ & n.s. \\
\hline Cube & $9.31(0.84)[7-10]$ & $7.87(2.6)[0-10]$ & $p<0.01$ \\
\hline Rey-Osterrieth figure - copy (36) & $31.04(6.2)$ [24.5-36] & $26.83(7.2)[12.5-36]$ & $p<0.01$ \\
\hline Benton line orientation test (30) & $23.96(4.4)[14-30]$ & $20.14(4.6)[11-29]$ & $p<0.01$ \\
\hline Benton facial recognition test & $45.58(3.1)[39-51]$ & $44.0(4.0)[37-51]$ & n.s. \\
\hline
\end{tabular}




\section{Stimuli}

In the current study 36 Caucasian unfamiliar individuals (18 women/18 men) presented in both frontal (top) and $3 / 4$ views ( $45^{\circ}$ angle, bottom) were used [see Experiment 3 in 33]. These photographs were processed to remove any external cues (such as hair and ears). Thirty-six pictures of cars presented in an upright position in frontal and $3 / 4$ views were also used as part of the stimuli and designed in an identical way. Many previous studies have used pictures of cars to isolate the FIE [30, 33, 40, 68]. Pictures of cars were used because they are familiar objects having multiple parts (e.g. headlights, mirrors, windshield, etc.) alike faces (e.g. eyes, nose, mouth). The stimuli were about $7.1^{\circ} \times 5.7^{\circ}$ for faces and $5 \times 7.8^{\circ}$ for cars. Pictures of cars were taken in Belgium 20 years ago (1996) and are mostly photographs of European and Japanese car models unknown to the participants, with car logos removed. All pictures were presented in shades of gray on a white background. From these pictures, 144 displays/trials were created. Each display consisted of 3 stimuli from the same category (faces or cars), one presented at the center of the upper half of the screen, and two horizontally-aligned stimuli presented in the lower half of the screen (left and right) (see Figure 1 for example). The sex was always the same for distractor and target faces. Each stimulus in the upper half of the screen was presented in a frontal view while the 2 stimuli in the lower half were presented in a $3 / 4$ view. One of the 2 stimuli presented in the bottom half of each trial matched the stimulus presented in the upper half, while the other stimulus presented in the bottom half was different, but could be the same stimulus shown in the center of the upper half of the screen in another trial. In addition, the exact same displays of faces and cars were presented upside-down, meaning that each face or car in the trial was shown in an inverted position. In total, there were 36 trials of upright cars, 36 of inverted cars, 36 of upright faces and 36 of inverted faces. 
Figure 1. Examples of different displays/trials of stimuli.
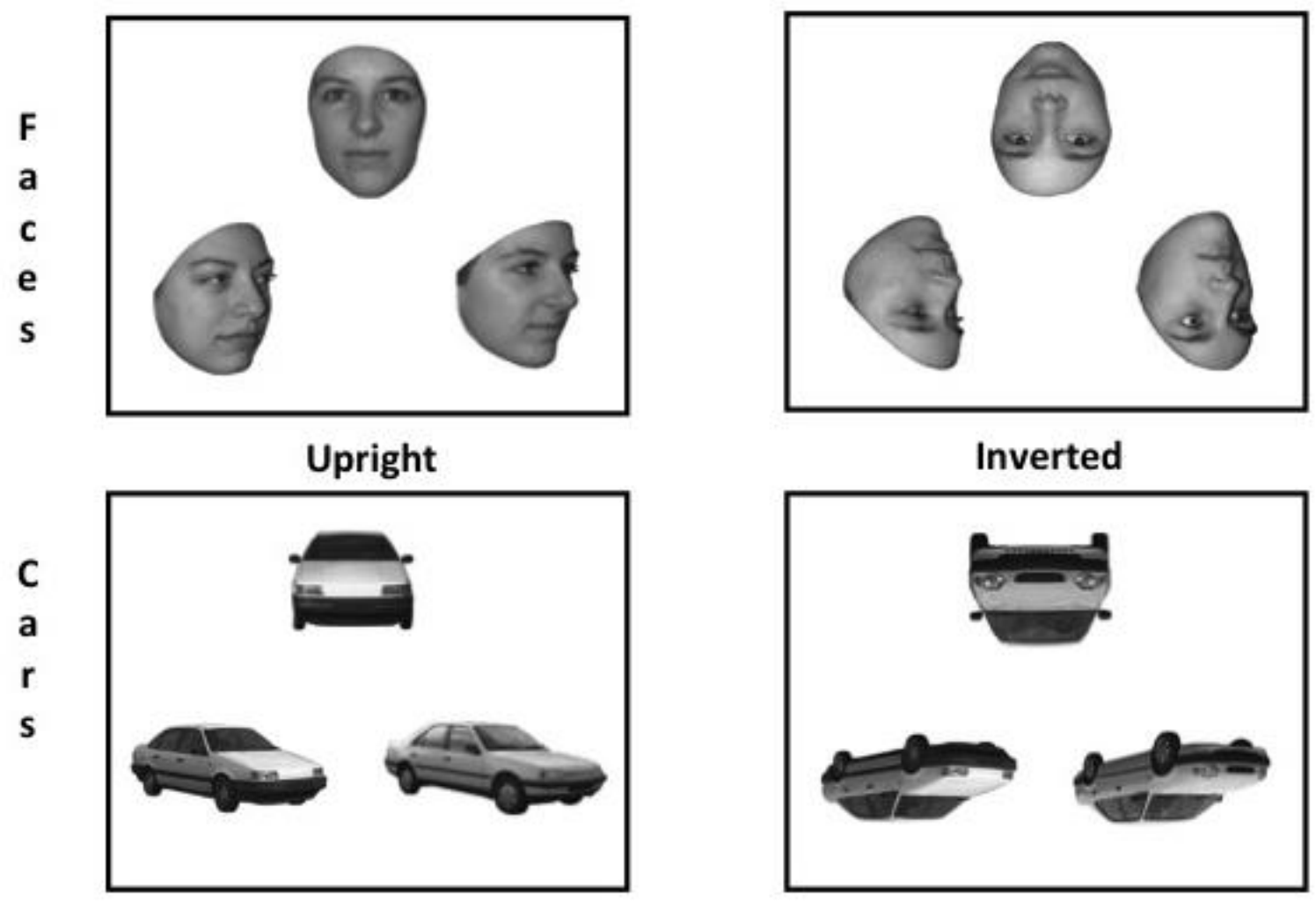

\section{Procedure}

The task was programmed with the E-Prime software (version 2.0.10.353). In this experiment, displays of faces and cars were presented to each participant on the computer screen. Participants had to select which of the two stimuli presented in the lower half of the screen matched the stimulus presented in the upper half of the screen. They were instructed to respond as accurately yet as fast as possible. Each display made of the 3 stimuli remained on the screen until the participant provided an answer by pressing one of the two response keys on the keyboard. The participant had to press the $S$ button if the corresponding stimulus was on the bottom left-hand side of the screen, and the $L$ button if it was on the right-hand side. Stimulus displays (i.e., one trial) were separated by 1,000 msec. The experiment was divided into 3 blocks containing 12 trials of each category (upright cars, inverted cars, upright faces and inverted faces) presented at random. The experiment began with a practice session 
consisting of 6 trials of upright and inverted faces, followed by the 144 trials of the experiment.

\section{Statistical analyses}

Statistical analyses were conducted with IBM SPSS Version 21.0 (Statistical Package for the Social Sciences). Practice trials were not included in the analyses.

The mean error rates (ER) and the mean response times (RT) were calculated for each condition and for each participant. RT were only used for successful trials and if RT did not exceed 1.96 standard deviations below or above a participant's own mean. Outliers were then replaced by the participant's mean RT (across all conditions), accounting for $5.5 \%$ of the data $[69,70]$

In regard to ER, we first verified whether scores exceeded 3.29 standard deviations above the mean and SD of all participants, which was not the case [71]. We also verified the normality of our variables according to Kline's criteria [72]. Only ER for inverted cars in HE exhibited abnormal kurtosis. However, as there were no participants with extreme scores on this variable, the distribution of this variable was not modified.

Inversion costs ratios (ICR) were also computed for ER and RT using the following formula for faces and for cars: ER or RT difference between upright and inverted condition divided by the sum of ER or RT of both conditions respectively. A negative ICR indicates that a participant performed more accurately with upright pictures than with inverted pictures and a positive ICR indicates the opposite pattern. ICR were used as a way to compare more accurately the difference between $\mathrm{HE}$ and $\mathrm{AD}$ patients by comparing the IE to its own condition and allowing it to be expressed in terms of a similar amplitude across individuals (speed/accuracy ratio, reduced speed of processing in AD, etc.). Also, by first comparing the 
participants with themselves, we can reduce the statistical bias that may be induced by a greater variance in $\mathrm{AD}$.

Analysis of variance for repeated measures (ANOVA) was performed separately for non-transformed data and ICR on both ER and RT. Mauchly's test for sphericity was conducted for each ANOVA to assess the homogeneity of variance and the analyses did not reveal any significant effect. Therefore, the ANOVAs were not corrected. ANOVAs on nontransformed data were run with Group (Controls vs. AD patients) as between subjects and Category (Cars vs. Faces) and Orientation (Upright vs. Inverted) as within subjects. ANOVAs on ICR were run with Group as between subjects and Category as within subjects.

Significant three-way interactions for non-transformed data were subsequently analyzed by running separated ANOVAs for each group with Category and Orientation as within subjects. Planned $t$ tests between upright cars and inverted cars, between upright faces and inverted faces, between upright cars and upright faces and between inverted cars and inverted faces were used as posthoc analysis to decompose significant interactions on nontransformed data and on ICR.

Finally, ICR were used to compute z scores for each AD patient compared to HE for cars and faces on both ER and RT according to this formula: (HEmean - ADratio)/HEsd with HEmean and HEsd reflecting the mean and standard deviation of the HE group for a given ICR and ADratio the specific value of a given AD patient for the given ICR.

A $p<.05$ was used as a significant threshold for all analyses.

A correlation analysis was also conducted between the ICR on ER for cars and faces and the different neuropsychological scores in the $\mathrm{AD}$ group and in the HE group in order to better understand the relations between performance on the task and specific cognitive processes. Due to the exploratory nature of this analysis, the threshold for significance was not corrected for multiple comparisons. The results are thus discussed accordingly. 


\section{Results}

The mean accuracy rates and correct RTs are illustrated in Figure 2A and 2B, respectively.

\section{Error Rates (ER)}

There were significant main effects of all factors: $\operatorname{Group}\left(F(1,46)=11.68, p<.05, \eta_{g}^{2}=.14\right)$ Category $\left(F(1,46)=142.47, p<.05, \eta_{g}^{2}=.30\right)$ and Orientation $(F(1,46)=74.78, p<.05$, $\left.\eta_{g}^{2}=.12\right)$, these effects being qualified by significant interactions between Orientation and $\operatorname{Group}\left(F(1,46)=4.82, p<.05, \eta_{g}^{2}=.01\right)$, as well as between Orientation and Category $\left(F(1,46)=16.59, p<.05, \eta_{g}^{2}=.05\right)$. Most importantly, the three-way interaction between Category, Orientation and Group was significant $\left(F(1,46)=4.07, p<.05, \eta_{g}^{2}=.01\right.$ ) (all other effects, $F<1$ ). This interaction, which was due to the much larger face inversion effect in HE participants (18.63\% for faces vs. $3.03 \%$ for cars) as compared to AD participants $(9.22 \%$ vs. 3.77\%), was decomposed by running separate ANOVAs for each group.

For HE, there was a main effect of Category $\left(F(1,22)=64.47, p<.05, \eta_{g}^{2}=.37\right)$ and of Orientation $\left(F(1,22)=61.73, p<.05, \eta_{g}^{2}=.25\right)$ and the Category by Orientation interaction was also significant $\left(F(1,22)=27.92, p<.05, \eta_{g}^{2}=.15\right)$, reflecting the much larger decrease in performance for faces than cars with inversion, even if there was a decrease in performance with inversion for both cars $(t(22)=2.39, p<.05)$ and faces $(t(22)=7.26$, $p<.05)$.

For $\mathrm{AD}$ patients, there was a main effect of Category $(F(1,22)=78.03, p<.05$, $\eta_{g}^{2}=.26$ ); cars were significantly better processed than faces, and a main effect of Orientation $\left(F(1,22)=20.92, p<.05, \eta_{g}^{2}=.05\right)$, whereby upright stimuli were better processed than inverted stimuli. However, the inversion effect did not differ significantly for faces and cars (i.e., non-significant interaction between Category and Orientation $(F(1,22)=1.81, p=.19)$. It should be noted that even in the inverted faces condition, which was the more difficult 
condition, AD patients performed well above chance level $(t(24)=4.20, p<.01$; patients' percentage error against $50 \%$ chance to choose the correct response).

\section{Response Times $(R T)$}

In regard to RT, there was a main effect of $\operatorname{Group}\left(F(1,46)=7.82, p<.05, \eta_{g}^{2}=.13\right)$, Category $\left(F(1,46)=21.57, p<.05, \eta_{g}^{2}=.02\right)$ and Orientation $(F(1,46)=34.31, p<.05$, $\left.\eta_{g}^{2}=.02\right)$, qualified by a significant three-way interaction between Group, Category, and Orientation $\left(F(1,46)=4.15, p<.05, \eta_{g}^{2}=0\right)$. All other interactions were not significant $(F<1)$. The three-way interaction was due to the much larger face inversion effect in $\mathrm{HE}$ participants (1,266.43 $\mathrm{ms}$ for faces $v s .545 .03 \mathrm{~ms}$ for cars $)$ as compared to AD participants (1,003.68 ms vs. $788.36 \mathrm{~ms}$ respectively). This interaction was decomposed by running an ANOVA in both groups separately.

For HE, there was a main effect of Category $\left(F(1,22)=23.68, p<.05, \eta^{2}{ }_{g}=.09\right)$ and Orientation $\left(F(1,22)=32.33, p<.05, \eta_{g}^{2}=.05\right)$, qualified by a significant interaction between Category and Orientation $\left(F(1,22)=6.42, p<.05, \eta_{g}^{2}=.01\right)$, due to the relatively larger increase of RT with inversion for faces $(t(22)=4.43, p<.05)$ than cars $(t(22)=5.60, p<.05)$.

For AD patients, the main effect of Category was significant $(F(1,24)=4.57, p<.05$, $\left.\eta_{g}^{2}=.01\right)$ revealing that faces were processed more slowly. The main effect of Orientation $\left(F(1,24)=12.27, p<.05, \eta_{g}^{2}=.02\right)$ was also significant indicating the upright stimuli were processed more quickly. Contrary to the HE group, however, the Category by Orientation interaction was not significant $(F<1)$, indicating that the inversion effect did not differ for faces and cars in $\mathrm{AD}$. 
Supplementary Figure 1. Percentage of errors for each control and patient as a function of the experimental condition.

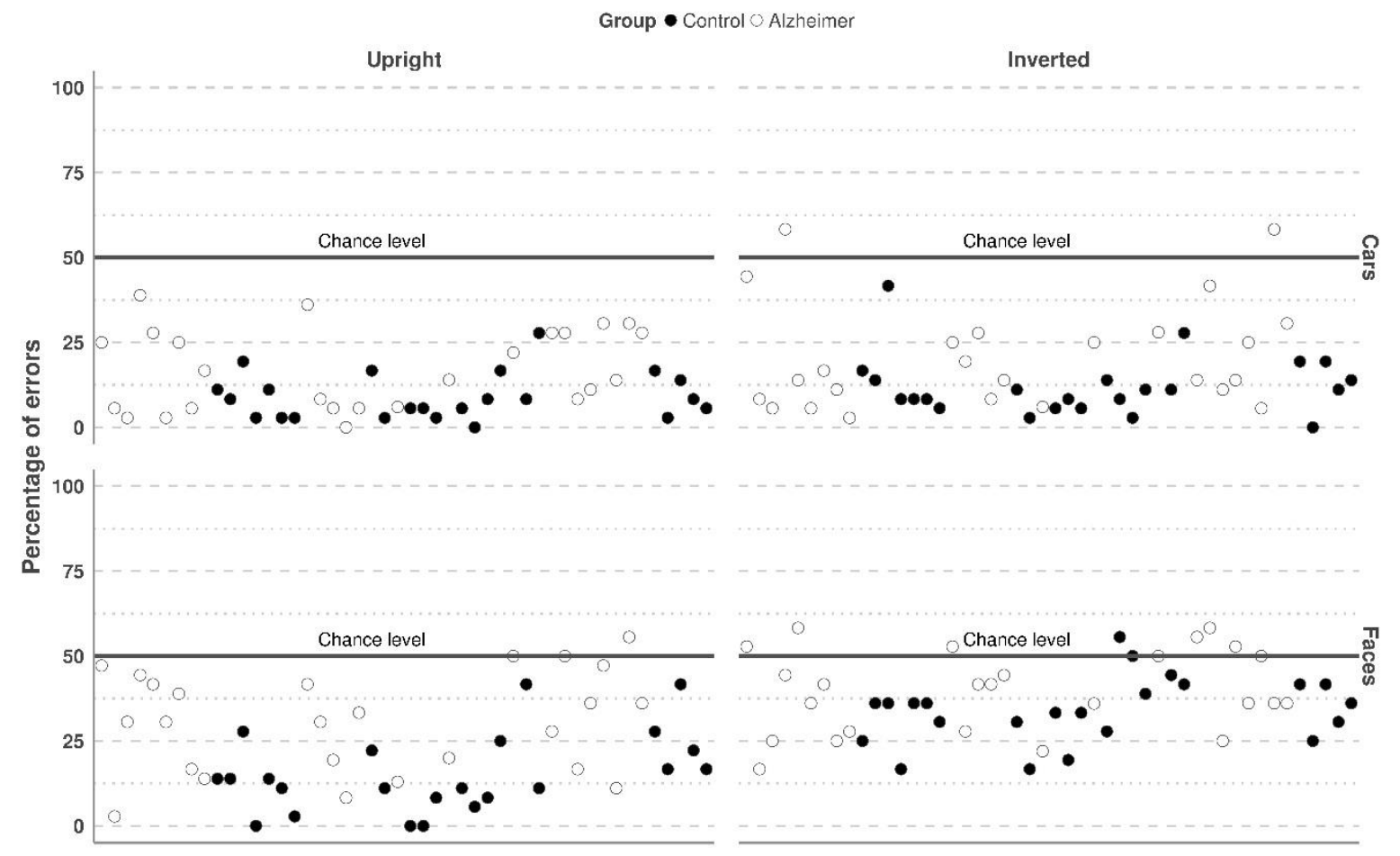

\section{Inversion Cost Ratio (ICR) analyses}

Since AD patients made many more mistakes and were much slower than normal controls, we also computed an inversion cost ratio (see methods) to normalize for general performance and speed. These inversion cost ratios are illustrated for the categories and groups in Figure 3. 
Figure 2. Mean error rates (Fig. 2A) and mean response time (Fig. 2B) of HE and AD participants across conditions (standard errors corrected for within participant design).
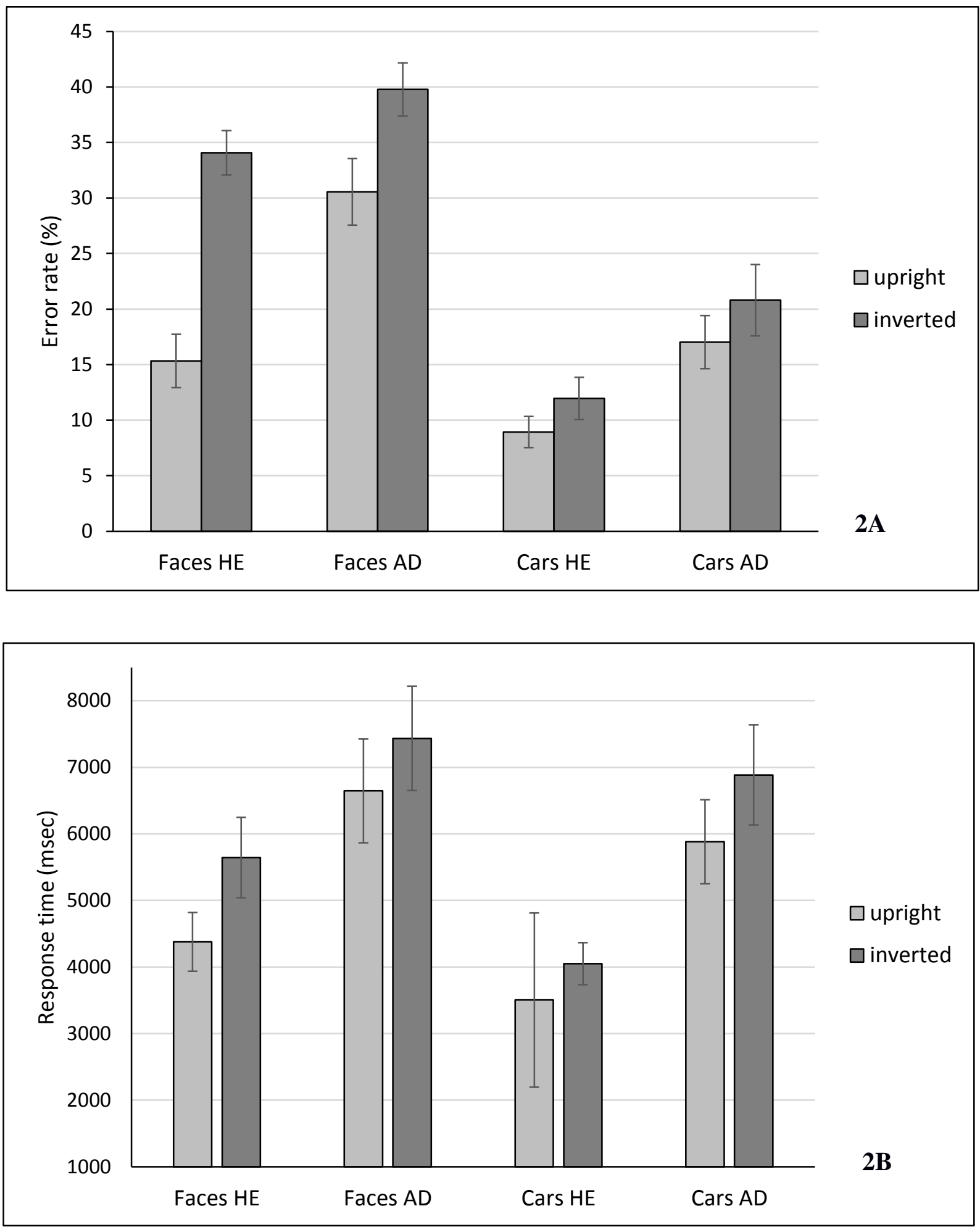


\section{Error Rates (ER)}

The main effect of Group showed a non-significant trend $\left(F(1,46)=3.74, p=.06, \eta_{g}^{2}=.05\right)$ and the main effect of Category was significant $\left(F(1,46)=8.35, \mathrm{p}<.05, \eta_{g}^{2}=.07\right)$, these effects being qualified by the significant interaction between Group and Category $\left(F(1,46)=4.66, p<.05, \eta_{g}^{2}=.04\right)$. To better understand this interaction, planned $t$ tests were performed for each category with group as the grouping variable. For cars, there was no significant difference between $\mathrm{AD}$ patients and $\mathrm{HE}(t(44)=.07, p=.95)$, whereas the ratio was significantly higher in $\mathrm{HE}(-0.45)$ than in $\mathrm{AD}(-0.17)$ for faces $(t(40)=3.37, p<.05)$.

This pattern of results was confirmed by a z-score analysis on ICR. AD patients were relatively evenly distributed around the performance of HE participants for cars (13 AD patients above 0 ) whereas only three AD patients were above the HE's performance for faces. In other words, almost all AD patients presented a diminished FIE compared to HE.

\section{Response Times (RT)}

The main effect of Group was not significant $(F(1,46)=1.50, p=.23)$ nor was the main effect of Category $(F<1)$. However, the Group by Category interaction showed a nonsignificant trend $\left(F(1,46)=3.20, p=.08, \eta_{g}^{2}=.03\right)$. Due to our a priori hypothesis and the trend for the interaction, this interaction was further explored with planned $t$ tests for each category with Group as the grouping variable. Results are presented in Figure 6.

As for ER, there was no significant difference between groups in ICR for cars, $t(45)=0.27, p=.79$. In line with error rate measures, the ICR, however, was higher for faces in the HE group (-0.11) compared to the AD group $(-0.06)(t(45)=1.70, p<.05)$.

This pattern of results was once again observed by the z-score analysis on ICR. AD patients were relatively evenly distributed around the performance of HE participants for cars 
(14 AD patients above 0) whereas only five AD patients were above the HE's performance for faces. As for ER, most of the AD patients presented a diminished FIE compared to HE.

Figures 3A and 3B. Mean inversion cost ratios (ICR) for error rates (ER) and response times (RT) in AD and HE participants (standard errors corrected for within participant design).
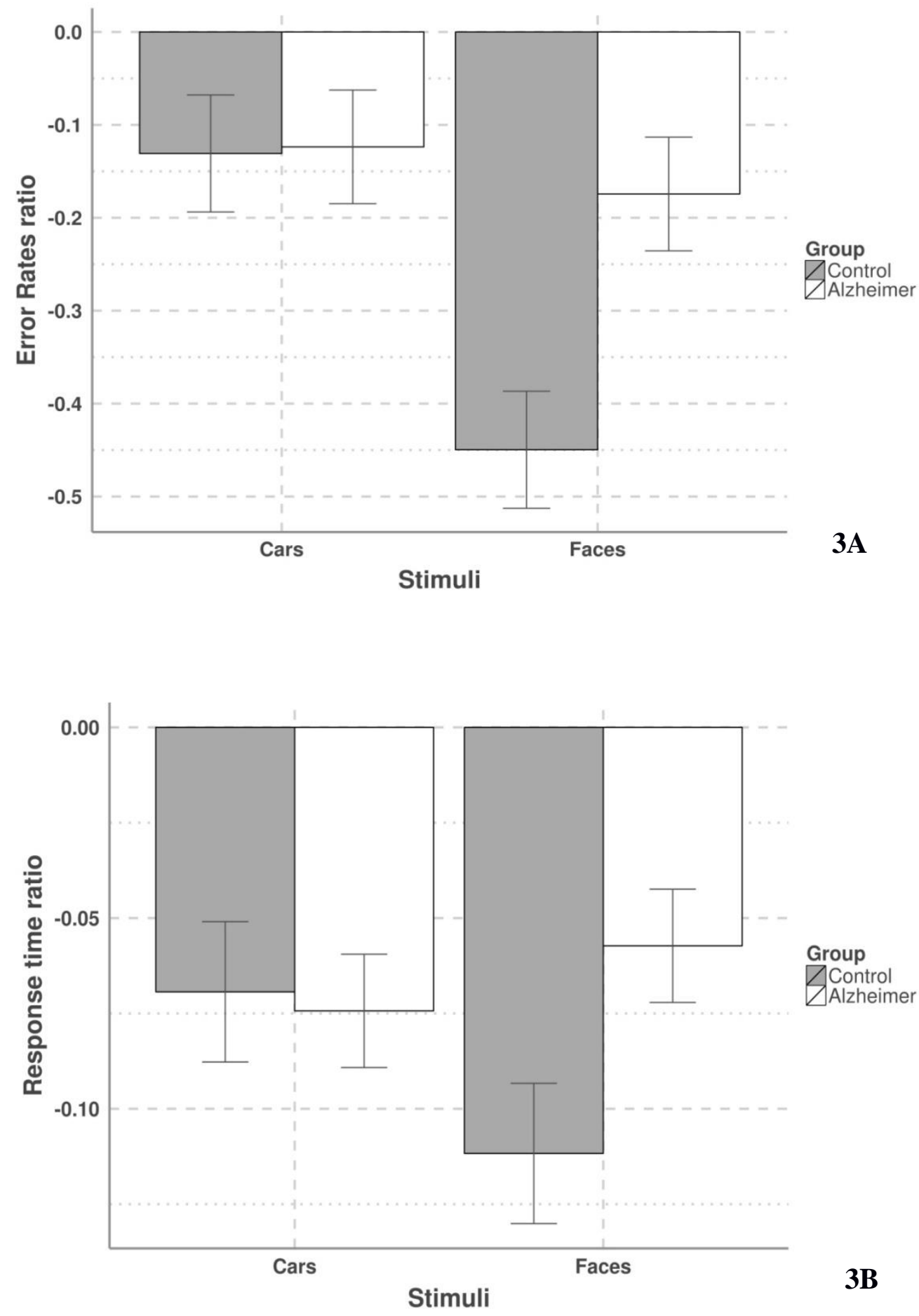


\section{Correlation analysis}

Pearson coefficients were computed to assess the relationship between the ICR on ER for cars and faces and neuropsychological tests in the AD group. A significant correlation was found between the ICR on ER for faces and performance on the Benton Facial Recognition Test $(\mathrm{r}=-.48, p<.05)$, copy of the Rey Figure $(\mathrm{r}=-.50, p<.05)$, recognition of words in the RL/RI $16(\mathrm{r}=-0.50, p<.05)$, and word-color interference in the Stroop test $(\mathrm{r}=-0.53$, $p<.05)$. All other correlations with neuropsychological tests were non-significant. Concerning cars, a significant correlation was found between the ICR on ER and performance on the Benton Line Orientation Test $(r=-.44, p<.05)$. The same correlations were also computed in the control group. A significant correlation was found between the ICR on ER for faces and performance on recognition of words in the RL/RI $16(\mathrm{r}=0.43, p<.05)$. All other correlations with neuropsychological tests were non-significant. Concerning pictures of cars, a significant correlation was found between the ICR on ER and performance on the Trail Making Test part A $(r=.43, p<.05)$.

\section{Discussion}

This study aimed to investigate if AD patients are specifically impaired at face perception. We addressed this question by comparing the matching/discrimination of simultaneously presented individual faces to other nonface familiar shapes, at both upright and inverted orientation. Most interestingly, AD patients had a reduced face inversion effect (FIE) both in terms of error rates and response times. Healthy participants showed a much larger decrease in performance for faces than for cars with inversion, while in $\mathrm{AD}$ the inversion effect did not differ significantly for faces and cars.

It is important to note that $\mathrm{AD}$ patients generally made more mistakes and were slowed down in all conditions tested in the study. In this respect, their impairment was not 
specific to (upright) faces. Even a simultaneous matching task such as the task used here involves many processes (attention, decision making, motor response, etc.) contributing to performance, so that any impairment at this task cannot be attributed unambiguously to perceptual processes. Since AD patients have a lower general cognitive functioning than typical participants, this factor may well account for the general increase of error rates and RTs in the different conditions. However, a strength of the present study is that these general processes are neutralized by comparing the different conditions, in order to isolate the specific processes involved in upright face perception. Moreover, the reduced FIE in AD cannot be accounted for in terms of a floor effect. AD's accuracy rates are low for upright faces $(69 \%)$ but they remain well above chance for inverted faces $(61 \%)$, indicating that there was still room for further decreases. Moreover, the FIE was also reduced when measures in correct RTs in AD patients. Therefore, the significant interactions between object categories, orientation and the two groups tested suggest that, in addition to their general difficulties and slowing down at performing behavioral tasks requiring matching complex visual stimuli, AD patients present with a specific impairment at building a visual representation of an (upright) individual face.

Face inversion deficits have been previously documented in other clinical populations, most notably patients suffering from acquired prosopagnosia, who show an absence or reduced face inversion effect $[32,33,73-76]$. Persons with unmedicated schizophrenia have also been documented to show lower FIE than controls [77], and a reduction of the FIE has also sometimes been reported in neurodevelopmental disorders such as autism, Down syndrome and Williams syndrome [78] although the vast majority of studies investigating the FIE in autism spectrum disorder (ASD) have concluded for a typical effect, despite lower overall performance and general cognitive functioning [79]. To our knowledge, however, no prior study has shown a reduced FIE in Alzheimer's disease. The current study provides new 
insights into the nature of the face processing difficulties encountered in $\mathrm{AD}$ and may explain, at least to a certain extent, some of the difficulties patients have in recognizing and identifying familiar and famous persons. Difficulties in recognizing familiar persons in $\mathrm{AD}$ are more often attributed to memory loss. Although AD patients undoubtedly show significant memory difficulties which may impair their ability to recognize recently-encountered individuals (episodic memory) as well as previously familiar and famous individuals (semantic memory), the results of this study suggest that even in the mild stage of the disease, patients also present with deficits in higher level visuoperceptual processes required to process faces. It is worth pointing out that facial skills are rarely assessed in clinical practice, although these skills are critical in the lives of persons with AD. Indeed patients need to recognize familiar persons in various contexts and be able to distinguish familiar from unfamiliar individuals. The development of new clinical tools that allow assessing various aspects of visuoperceptual face processes may thus be particularly relevant and useful to clinicians.

Interestingly, $\mathrm{AD}$ patients in the current study were not impaired on the Benton Facial Recognition Test (BFRT). The BFRT is a commonly used clinical tool used to test the ability of an individual to match faces presented in identical and different perspectives. These results contrast with other studies that have shown significant differences between $\mathrm{HE}$ and $\mathrm{AD}$ participants on this test [26-28]. The absence of impairment on the BFRT in our AD group may have different explanations. First of all, AD patients in the current study were in a mild stage of the disease, while previous studies included patients in a more advanced stage [27]. Second, as in most studies we did not measure response times for the BFRT. However, there is evidence that this variable is important in assessing face matching ability using the BFRT, since some patients with acquired prosopagnosia can achieve reasonable scores at this test if they are given unlimited time [74]. Therefore, if we had measured RT it is possible that we 
may have obtained significantly slower RT in AD relative to $\mathrm{HE}$ on the BFRT despite not finding a significant difference in accuracy.

Despite the lack of difference between AD and healthy controls on accuracy rates at the BFRT, performance on the BFRT was significantly and specifically correlated with the ICR for faces in AD patients: the weaker the performance at the BFRT, the lower the FIE. This suggests that processes involved in the BFRT and the face inversion test are related, but that the face inversion test used here is more sensitive in detecting face perception difficulties in mild AD.

In the current study, $\mathrm{AD}$ patients showed a specific significant decrement in matching/discriminating upright faces relative to inverted faces and nonface shapes. There is overwhelming evidence that the processing of upright faces differ from other types of stimuli - including inverted faces - since it involves fine-grained holistic representations: the multiple parts of an individual face are perceived as integrated, or as a single unit, rather than as separate representations $[44,45,80-83]$. Our original data suggest that this process may be partly compromised in $\mathrm{AD}$ patients, who may rely to a greater extent on analytical (i.e., parby-part) processes in order to recognize faces (i.e. relying to a greater extent on isolated features such as the eyes, the nose and the mouth). A deficit in forming individualized, integrated representations of faces based on their local features may in turn impede the identification of faces.

At the neuroanatomical level, one possible explanation for the difficulties in face perception observed in $\mathrm{AD}$ patients in the current study is that regions specifically associated with face perception may be affected during the course of the disease. An important region involved in face processing is the fusiform face area [FFA, 84], located in the lateral section of the posterior/middle fusiform gyrus, with a right hemispheric dominance. This region is sensitive to differences between individual faces [e.g., 85, 86] and shows a large inversion 
effect (i.e. reduction of release from adaptation to presentation of the same face when it is presented upside-down) [87-89]. One study, which used functional magnetic resonance imaging (fMRI) during a face-matching task, detected a weaker correlation between activation of the right and left fusiform gyrus in patients with Mild cognitive impairment (MCI, considered to be a prodromal stage of AD) and healthy controls [90]. This suggests that the fusiform gyrus is less activated in MCI during the task, even though there was no difference in behavioral performance between the two groups in that study [90]. Another fMRI study showed that the patterns of activation in the right FFA and right occipital face area (OFA), a face-selective area of the lateral part of the inferior occipital gyrus that is also critically involved in individualization of faces [85, 86, 89], were abnormal in MCI [91]. In fact, these regions were activated more strongly in response to scrambled faces vs. real faces, showing a pattern opposite to that of controls participants. Interestingly, the authors explained this pattern by suggesting that the holistic processing controlled by these regions was impaired in MCI [91]. More recently, a meta-analysis of gray matter volume in AD detected that AD individuals, unlike HE, usually have right fusiform gyrus atrophy [92]. Difficulties in recognizing faces for $\mathrm{AD}$ also seem consistent with studies showing that the $\mathrm{N} 170$, an early ERP component that is larger to faces than objects [93] and sensitive to individual face repetition [94 for review], is of reduced amplitude in $\operatorname{AD}[95,96]$. Thus, these alterations in face-selective brain regions and scalp electrophysiological responses could possibly subtend the behavioral face perception deficit that we report in AD.

Finally, some limitations need to be mentioned in the current study. Although we showed a reduced FIE in AD patients, the study did not include a questionnaire to assess face recognition difficulties of patients in everyday life situations [e.g., 97]. Therefore, it is difficult to determine if the reduced FIE is actually related to real-life difficulties in AD patients (even though we assume this is the case), and whether there is a given FIE cut-off 
beyond which face recognition difficulties become apparent and have a functional impact on the lives of patients. Future studies should address this question in order to better understand the functional impact of face-processing difficulties in the everyday life of AD patients. Finally, the correlation analyses carried out in the current study were exploratory in nature and for this reason were not corrected for multiple comparisons. Therefore they need to be considered as preliminary results and will need to be further supported in future studies.

In conclusion, results of the present study suggest that, in addition to their memory impairment, AD patients have deficits in higher-level visual processes, more specifically at the level of the perception of individual faces. Future studies should help at better characterizing and pinpointing the nature of the face recognition deficits in this clinical population. Finally, future functional and structural neuroimaging studies should investigate the neural correlates of this reduced face inversion effect in AD. 


\section{Acknowledgements}

Sven Joubert and Isabelle Rouleau are supported by the Alzheimer Society of Canada. Sven Joubert is also supported by a Chercheur-boursier senior award from the Fonds de recherche du Québec en santé (FRQ-S). Delphine Gandini was supported by a CIHR postdoctoral award and Guillaume Vallet is supported by a FRQ-S postdoctoral award. Bruno Rossion is supported by the Belgian National Fund for Scientific research and a BELSPO grant (PAI/UIAP $\left.\mathrm{n}^{\circ} \mathrm{P} 7 / 33\right)$. We are particularly grateful to Karine Thorn who helped in the recruitment $\mathrm{AD}$ patients. We also wish to thank all participants who took part in the study. 


\section{References}

[1] Ferri CP, Prince M, Brayne C, Brodaty H, Fratiglioni L, Ganguli M, Hall K, Hasegawa K, Hendrie H, Huang Y, Jorm A, Mathers C, Menezes PR, Rimmer E, Scazufca M, Alzheimer's Disease I (2005) Global prevalence of dementia: a Delphi consensus study. Lancet 366, 2112-2117.

[2] Robakis NK (2015) Molecular Neuropathology of Alzheimer Dementia and Therapeutic Approaches In GeNeDis 2014 Springer, pp. 1-1.

[3] Fardoun HM, Mashat AA, Ramirez Castillo J (2015) Recognition of familiar people with a mobile cloud architecture for Alzheimer patients. Disability \& Rehabilitation, $1-5$.

[4] Werheid K, Clare L (2007) Are faces special in Alzheimer's disease? Cognitive conceptualisation, neural correlates, and diagnostic relevance of impaired memory for faces and names. Cortex 43, 898-906.

[5] Becker JT, Lopez OL, Boller F (1995) Understanding impaired analysis of faces by patients with probable Alzheimer's disease. Cortex 31, 129-137.

[6] Nguyen VQ, Gillen DL, Dick MB (2014) Memory for unfamiliar faces differentiates mild cognitive impairment from normal aging. Journal of clinical and experimental neuropsychology 36, 607-620.

[7] Seelye AM, Howieson DB, Wild KV, Moore MM, Kaye JA (2009) Wechsler Memory Scale-III Faces test performance in patients with mild cognitive impairment and mild Alzheimer's disease. Journal of Clinical \& Experimental Neuropsychology: Official Journal of the International Neuropsychological Society 31, 682-688.

[8] Greene JD, Hodges JR (1996) Identification of famous faces and famous names in early Alzheimer's disease. Relationship to anterograde episodic and general semantic memory. Brain 119, 111-128.

[9] Joubert S, Brambati SM, Ansado J, Barbeau EJ, Felician O, Didic M, Lacombe J, Goldstein R, Chayer C, Kergoat M-J (2010) The cognitive and neural expression of semantic memory impairment in mild cognitive impairment and early Alzheimer's disease. Neuropsychologia 48, 978-988.

[10] Joubert S, Felician O, Barbeau EJ, Didic M, Poncet M, Ceccaldi M (2008) Patterns of semantic memory impairment in mild cognitive impairment. Behavioural neurology 19, 35-40.

[11] Armstrong R, Kergoat H (2015) Oculo-visual changes and clinical considerations affecting older patients with dementia. Ophthalmic \& Physiological Optics 35, 352376.

[12] Uhlhaas PJ, Pantel J, Lanfermann H, Prvulovic D, Haenschel C, Maurer K, Linden DE (2008) Visual perceptual organization deficits in Alzheimer's dementia. Dementia \& Geriatric Cognitive Disorders 25, 465-475.

[13] Rizzo M, Anderson SW, Dawson J, Myers R, Ball K (2000) Visual attention impairments in Alzheimer's disease. Neurology 54, 1954-1959.

[14] Toner CK, Reese BE, Neargarder S, Riedel TM, Gilmore GC, Cronin-Golomb A (2012) Vision-fair neuropsychological assessment in normal aging, Parkinson's disease and Alzheimer's disease. Psychology \& Aging 27, 785-790.

[15] Keri S, Antal A, Kalman J, Janka Z, Benedek G (1999) Early visual impairment is independent of the visuocognitive and memory disturbances in Alzheimer's disease. Vision Research 39, 2261-2265.

[16] Mendez MF, Mendez M, Martin R, Smyth KA, Whitehouse P (1990) Complex visual disturbances in Alzheimer's disease. Neurology 40, 439-439. 
[17] Hargrave R, Maddock RJ, Stone V (2002) Impaired recognition of facial expressions of emotion in Alzheimer's disease. Journal of Neuropsychiatry \& Clinical Neurosciences 14, 64-71.

[18] Hot P, Klein-Koerkamp Y, Borg C, Richard-Mornas A, Zsoldos I, Paignon Adeline A, Thomas Anterion C, Baciu M (2013) Fear recognition impairment in early-stage Alzheimer's disease: when focusing on the eyes region improves performance. Brain \& Cognition 82, 25-34.

[19] Kumfor F, Sapey-Triomphe LA, Leyton CE, Burrell JR, Hodges JR, Piguet O (2014) Degradation of emotion processing ability in corticobasal syndrome and Alzheimer's disease. Brain 137, 3061-3072.

[20] Roudier M, Marcie P, Grancher AS, Tzortzis C, Starkstein S, Boller F (1998) Discrimination of facial identity and of emotions in Alzheimer's disease. Journal of the Neurological Sciences 154, 151-158.

[21] Spoletini I, Marra C, Di Iulio F, Gianni W, Sancesario G, Giubilei F, Trequattrini A, Bria P, Caltagirone C, Spalletta G (2008) Facial emotion recognition deficit in amnestic mild cognitive impairment and Alzheimer disease. American Journal of Geriatric Psychiatry 16, 389-398.

[22] Torres B, Santos RL, Sousa MFBd, Simões Neto JP, Nogueira MML, Belfort TT, Dias R, Dourado MCN (2015) Facial expression recognition in Alzheimer's disease: a longitudinal study. Arquivos de Neuro-Psiquiatria 73, 383-389.

[23] Moyse E, Bastin C, Salmon E, Bredart S (2015) Impairment of age estimation from faces in Alzheimer's disease. Journal of Alzheimer's Disease 45, 631-638.

[24] Adduri CA, Marotta JJ (2009) Mental rotation of faces in healthy aging and Alzheimer's disease. PLoS ONE [Electronic Resource] 4, e6120.

[25] Benton A, Van Allen M (1968) Impairment in facial recognition in patients with cerebral disease. Cortex 4, 344-IN341.

[26] Della Sala S, Muggia S, Spinnler H, Zuffi M (1995) Cognitive modelling of face processing: evidence from Alzheimer patients. Neuropsychologia 33, 675-687.

[27] Kurth S, Moyse E, Bahri MA, Salmon E, Bastin C (2015) Recognition of personally familiar faces and functional connectivity in Alzheimer's disease. Cortex 67, 59-73.

[28] Tippett LJ, Blackwood K, Farah MJ (2003) Visual object and face processing in mildto-moderate Alzheimer's disease: from segmentation to imagination. Neuropsychologia 41, 453-468.

[29] Cronin-Golomb A, Gilmore GC, Neargarder S, Morrison SR, Laudate TM (2007) Enhanced stimulus strength improves visual cognition in aging and Alzheimer's disease. Cortex 43, 952-966.

[30] Yin RK (1969) Looking at upside-down faces. Journal of experimental psychology 81, 141.

[31] Ashworth III AR, Vuong QC, Rossion B, Tarr MJ (2008) Recognizing rotated faces and Greebles: What properties drive the face inversion effect? Visual Cognition 16, 754-784.

[32] Busigny, Joubert, Felician, Ceccaldi, Rossion (2010) Holistic perception of the individual face is specific and necessary: Evidence from an extensive case study of acquired prosopagnosia. Neuropsychologia 48, 4057-4092.

[33] Busigny, Rossion (2010) Acquired prosopagnosia abolishes the face inversion effect. Cortex 46, 965-981.

[34] Diamond R, Carey S (1986) Why faces are and are not special: an effect of expertise. Journal of Experimental Psychology: General 115, 107.

[35] Husk JS, Bennett PJ, Sekuler AB (2007) Inverting houses and textures: Investigating the characteristics of learned inversion effects. Vision Research 47, 3350-3359. 
[36] Leder H, Carbon CC (2006) Face - specific configural processing of relational information. British Journal of Psychology 97, 19-29.

[37] Loftus GR, Oberg MA, Dillon AM (2004) Linear theory, dimensional theory, and the face-inversion effect. Psychological Review 111, 835.

[38] Rakover SS, Cahlon B (2014) A Possible Correction of the Face Inversion Effect: A Methodological Commentary. The American journal of psychology 127, 303-311.

[39] Robbins R, McKone E (2007) No face-like processing for objects-of-expertise in three behavioural tasks. Cognition 103, 34-79.

[40] Rossion B, Curran T (2010) Visual expertise with pictures of cars correlates with RT magnitude of the car inversion effect. Perception 39, 173.

[41] Rossion B, Gauthier I (2002) How does the brain process upright and inverted faces? Behavioral and cognitive neuroscience reviews 1, 63-75.

[42] Scapinello KF, Yarmey AD (1970) The role of familiarity and orientation in immediate and delayed recognition of pictorial stimuli. Psychonomic Science 21, 329330 .

[43] Valentine $\mathrm{T}$, Bruce $\mathrm{V}$ (1986) The effects of distinctiveness in recognising and classifying faces. Perception 15, 525-535.

[44] Rossion B (2008) Picture-plane inversion leads to qualitative changes of face perception. Acta psychologica 128, 274-289.

[45] Sergent J (1984) An investigation into component and configural processes underlying face perception. British Journal of Psychology 75, 221-242.

[46] Barton JJ, Keenan JP, Bass T (2001) Discrimination of spatial relations and features in faces: Effects of inversion and viewing duration. British journal of psychology $\mathbf{9 2}$, 527-549.

[47] Collishaw SM, Hole GJ (2000) Featural and configurational processes in the recognition of faces of different familiarity. Perception 29, 893-909.

[48] Freire A, Lee K, Symons LA (2000) The face-inversion effect as a deficit in the encoding of configural information: Direct evidence. PERCEPTION-LONDON- 29, 159-170.

[49] Laguesse R, Dormal G, Biervoye A, Kuefner D, Rossion B (2012) Extensive visual training in adulthood significantly reduces the face inversion effect. $J$ Vis $\mathbf{1 2}, 14$.

[50] Le Grand R, Mondloch CJ, Maurer D, Brent HP (2001) Neuroperception: Early visual experience and face processing. Nature 410, 890-890.

[51] Leder H, Bruce V (2000) When inverted faces are recognized: The role of configural information in face recognition. The Quarterly Journal of Experimental Psychology: Section A 53, 513-536.

[52] Mondloch CJ, Lewis TL, Budreau DR, Maurer D, Dannemiller JL, Stephens BR, Kleiner-Gathercoal KA (1999) Face perception during early infancy. Psychological Science 10, 419-422.

[53] Rhodes G, Brake S, Atkinson AP (1993) What's lost in inverted faces? Cognition 47, 25-57.

[54] Farah MJ, Tanaka JW, Drain HM (1995) What causes the face inversion effect? Journal of Experimental Psychology: Human Perception \& Performance 21, 628-634.

[55] Rossion B, Boremanse A (2008) Nonlinear relationship between holistic processing of individual faces and picture-plane rotation: evidence from the face composite illusion. Journal of Vision 8, 3.1-13.

[56] McKhann G, Drachman D, Folstein M, Katzman R, Price D, Stadlan EM (1984) Clinical diagnosis of Alzheimer's disease Report of the NINCDS - ADRDA Work Group* under the auspices of Department of Health and Human Services Task Force on Alzheimer's Disease. Neurology 34, 939-939. 
[57] Folstein MF, Folstein SE, McHugh PR (1975) "Mini-mental state": a practical method for grading the cognitive state of patients for the clinician. Journal of psychiatric research 12, 189-198.

[58] Van der Linden M, Coyette F, Poitrenaud J, Kalafat M, Calicis F, Wyns C, Adam S (2004) L'épreuve de rappel libre/rappel indicé à 16 items (RL/RI-16), Solal.

[59] Rey A (1960) Test de la figure complexe de Rey. Paris: Les Editions du Centre de Psychologie AppliqueÂe.

[60] Barbeau E, Didic M, Tramoni E, Felician O, Joubert S, Sontheimer A, Ceccaldi M, Poncet M (2004) Evaluation of visual recognition memory in MCI patients. Neurology 62, 1317-1322.

[61] Deloche G, Hannequin D (1997) Test de dénomination orale d'images: DO 80, Éd. du Centre de psychologie appliquée.

[62] Cardebat D, Doyon B, Puel M, Goulet P, Joanette Y (1990) Evocation lexicale formelle et sémantique chez des sujets normaux. Performances et dynamiques de production en fonction du sexe, de l'âge et du niveau d'étude. Acta Neurologica Belgica 90, 207-217.

[63] Reitan RM (1955) The relationship of the Trail Making Test to organic brain damage. Journal of Consulting Psychology 19, 393-394.

[64] Regard M (1984) Cognitive rigidity and flexibility: A neuropsychological study.

[65] Wechsler D (2001) Echelle clinique de mémoire de Wechsler MEM-III (WMS-III). Paris: Les éditions du Centre de Psychologie appliquée.

[66] Warrington EK, James M (1991) The visual object and space perception battery, Thames Valley Test Company Bury St Edmunds.

[67] Benton AL, Varney NR, deS Hamsher K (1978) Visuospatial judgment: A clinical test. Archives of Neurology 35, 364-367.

[68] Pallett PM, Meng M (2015) Inversion effects reveal dissociations in facial expression of emotion, gender, and object processing. Frontiers in Psychology 6.

[69] Cousineau D, Chartier S (2010) Outliers detection and treatment: a review. International Journal of Psychological Research 3, 58-67.

[70] Tabachnik BG, Fidell LS (2007) Using Multivariate Statistics, Pearson, Boston.

[71] Field A (2013) Discovering statistics using IBM SPSS statistics, Sage.

[72] Kline R (1998) Principles and Practice of Structural Equation Modeling (Guilford, New York, NY).

[73] Boutsen L, Humphreys GW (2002) Face context interferes with local part processing in a prosopagnosic patient. Neuropsychologia 40, 2305-2313.

[74] Delvenne J-F, Seron X, Coyette F, Rossion B (2004) Evidence for perceptual deficits in associative visual (prosop) agnosia: A single-case study. Neuropsychologia 42, 597 612.

[75] Marotta JJ, McKeeff TJ, Behrmann M (2002) The effects of rotation and inversion on face processing in prosopagnosia. Cognitive Neuropsychology 19, 31-47.

[76] McNeil JE, Warrington EK (1991) Prosopagnosia: A reclassification. The Quarterly Journal of Experimental Psychology 43, 267-287.

[77] Fakra E, Jouve E, Guillaume F, Azorin J-M, Blin O (2015) Relation between facial affect recognition and configural face processing in antipsychotic-free schizophrenia. Neuropsychology 29, 197.

[78] Dimitriou D, Leonard H, Karmiloff - Smith A, Johnson MH, Thomas MS (2015) Atypical development of configural face recognition in children with autism, Down syndrome and Williams syndrome. Journal of Intellectual Disability Research 59, 422-438. 
[79] Weigelt S, Koldewyn K, Kanwisher N (2012) Face identity recognition in autism spectrum disorders: a review of behavioral studies. Neurosci Biobehav Rev 36, 10601084.

[80] Biederman I, Kalocsais P (1997) Neurocomputational bases of object and face recognition. Philosophical Transactions of the Royal Society B: Biological Sciences 352, 1203-1219.

[81] Farah MJ, Wilson KD, Drain M, Tanaka JN (1998) What is" special" about face perception? Psychological review 105, 482.

[82] Rossion B (2009) Distinguishing the cause and consequence of face inversion: The perceptual field hypothesis. Acta psychologica 132, 300-312.

[83] Rossion B (2013) The composite face illusion: A whole window into our understanding of holistic face perception. Visual Cognition 21, 139-253.

[84] Kanwisher N, McDermott J, Chun MM (1997) The fusiform face area: a module in human extrastriate cortex specialized for face perception. The Journal of Neuroscience 17, 4302-4311.

[85] Gauthier I, Tarr MJ, Moylan J, Skudlarski P, Gore JC, Anderson AW (2000) The fusiform "face area" is part of a network that processes faces at the individual level. Journal of cognitive neuroscience 12, 495-504.

[86] Schiltz C, Rossion B (2006) Faces are represented holistically in the human occipitotemporal cortex. Neuroimage 32, 1385-1394.

[87] Goffaux V, Rossion B, Sorger B, Schiltz C, Goebel R (2009) Face inversion disrupts the perception of vertical relations between features in the right human occipito temporal cortex. Journal of Neuropsychology 3, 45-67.

[88] Mazard A, Schiltz C, Rossion B (2006) Recovery from adaptation to facial identity is larger for upright than inverted faces in the human occipito-temporal cortex. Neuropsychologia 44, 912-922.

[89] Yovel G, Kanwisher N (2005) The neural basis of the behavioral face-inversion effect. Current Biology 15, 2256-2262.

[90] Bokde A, Lopez-Bayo P, Meindl T, Pechler S, Born C, Faltraco F, Teipel S, Möller HJ, Hampel H (2006) Functional connectivity of the fusiform gyrus during a facematching task in subjects with mild cognitive impairment. Brain 129, 1113-1124.

[91] Graewe B, Lemos R, Ferreira C, Santana I, Farivar R, De Weerd P, Castelo-Branco M (2013) Impaired processing of 3D motion-defined faces in mild cognitive impairment and healthy aging: an fMRI study. Cerebral Cortex 23, 2489-2499.

[92] Wang WY, Yu JT, Liu Y, Yin RH, Wang HF, Wang J, Tan L, Radua J, Tan L (2015) Voxel-based meta-analysis of grey matter changes in Alzheimer's disease. Translational Neurodegeneration 4, 6.

[93] Bentin S, Allison T, Puce A, Perez E, McCarthy G (1996) Electrophysiological studies of face perception in humans. Journal of cognitive neuroscience 8, 551-565.

[94] Rossion B, Jacques C (2011) The N170: Understanding the Time Course. The Oxford handbook of event-related potential components, 115.

[95] Cheng PJ, Pai MC (2010) Dissociation between recognition of familiar scenes and of faces in patients with very mild Alzheimer disease: an event-related potential study. Clinical Neurophysiology 121, 1519-1525.

[96] Feuerriegel D, Churches O, Hofmann J, Keage HA (2015) The N170 and face perception in psychiatric and neurological disorders: A systematic review. Clinical Neurophysiology 126, 1141-1158.

[97] Shah P, Gaule A, Sowden S, Bird G, Cook R (2015) The 20-item prosopagnosia index (PI20): a self-report instrument for identifying developmental prosopagnosia. Royal Society Open Science 2, 140343. 
